\title{
APPLICATION OF THE DISPUTATION TECHNIQUE TO ENHANCE STUDENT'S SELF-ESTEEM
}

\author{
Rahimi Che Aman \\ School of Educational Studies, Universiti Sains Malaysia : rahimi@usm.my \\ Dzilal Abdul Aziz \\ Faculty of Educational Study, Universiti Putra Malaysia; dzilal@gmail.com
}

\begin{abstract}
This study aims to identify the effect of the disputation technique to enhance self-esteem in a student with low academic performance. Apart from that, this study also uncovers the symptoms of low selfesteem and the level of self-esteem in a student. A subject was chosen through purposive sampling technique. The subject was selected based on various predetermined criteria. The research comprised six counselling sessions. The qualitative data was collected throughout the counselling sessions using the transcription of the counselling sessions, observation list and quantitative data collected using the Rosenberg Self-Esteem Scale. The data were then analyzed using descriptive analysis and content analysis. The result showed that the student's level of self-esteem increased. As a conclusion, the symptoms of low self-esteem have also been successfully identified, and the result shows that the application of the disputation technique is effective in enhancing the self-esteem of a student with low academic performance through cognitive, emotion and behavior analysis.
\end{abstract}

Keywords: disputation technique, self-esteem, counselling

\section{Introduction}

Low academic performance is believed to lower the self-esteem of students due to irrational beliefs held by the student (Nielsen and Horan, 1996). Low self-esteem will affect the future of the students in term of self-concept and self-confidence if the level of self-esteem is not improved (Shokraii-Rees, 2003). The approach chosen to be used to help increase the level of the student's self-esteem is the disputation technique based on the Rational Emotive Behaviour Therapy (REBT).

\section{Research Background}

Adolescence is an intense time of emotional and physical change in a young person's life (McClure, Tanski \& Kingsbury, 2010). It is during this period that adolescents begin to develop a positive or negative perception of themselves. Based on a recent study, adolescents are experiencing more social and psychological problems than ever before (Mc Namara, 2000). These trends show an increased pressure that adolescents face which will ultimately tear down the walls of confidence and diminishes one's self-esteem (Mc Namara, 2000).

An adolescent spent a great amount of time per day in school. Thus, no aspect of school life, be it in the realm of academic achievement or social acceptance leaves a child's self-esteem untouched. The development of high self-esteem and high academic achievement can lead to an improved quality of life (Shokraii-Rees, 2003). Many adolescents are stressed daily due to low grade and test scores. Academic performance, academic achievement and social adjustment influence children's self-esteem (Henderson, 1991). The term self-esteem refers to how the beliefs and personal attributes that people have about themselves can affect them (McClure, Tanski \& Kingsbury, 2010). Starting from these beliefs, judgements and feelings are formed about their capabilities and worth. Over time, children create and assemble feelings that people have about their own capabilities and self-worth that they can articulate to others as their self-esteem. Jordan, Spencer \& Zanna (2005) stated that self-esteem is a product of an individual's own sense of their achievements and aspirations. Therefore, people who perceive themselves as successful in areas of their aspirations should have higher self-esteem than people with lower self-assessments.

The process of formal education can have a profound effect on a child's self-esteem as the child must master specific learning skills which are evaluated through the academic assessment carried out in schools. Thus, low academic performance will affect the self-esteem of an adolescent due to 
irrational belief the student has which resulted from the negative correlation between irrational belief and self-esteem (Sava \& Maricułoiu, 2011).

Nielsen and Horan (1996) found that these two specific irrational beliefs have continued to predict low self-esteem in the young population. One of the irrational belief is the demand for approval where they need love and approval from those significant to them, and they must avoid disapproval from any source. The next irrational belief is that in order to be a worthwhile person, they must achieve and succeed at whatever they do and make no mistakes. Thus, the irrational beliefs a student has about his poor academic performance will have a negative impact which will lower his self-esteem.

\section{Problem Statement}

Low self-esteem during the developmental period of adolescence could result in a variety of risks, such as juvenile delinquency, teenage pregnancy, drug abuse and depression (Hamacheck, 1990). These factors cause adolescence to be a crucial time for awareness and concern about self-esteem. The development of high self-esteem and high academic achievement can lead to an improved quality of life (Shokraii-Rees, 2003).

Hamacheck (1990) explored the condition under which success and failure in academic performance affect a person's self-evaluation. They reported the common-sense view that those who underachieve academically, or who fail to live up to their own academic expectations, suffer significant losses in self-esteem. Students tend to behave in ways that are consistent with their beliefs about themselves and their expectations for future success or failure (May, 2002). One of the key issues in Rational Emotive Behaviour Therapy (REBT) (Ellis, 1994) is identifying and disputing core irrational beliefs and replacing them with rational beliefs. The positive consequences of this approach on various mental health issues have been widely underlined using adolescents and children as samples (Gonzales, Nelson, Gutkin et al., 2004; Hajzler \& Bernard, 1991).

Greiger (1990) suggested that certain irrational beliefs influence the development of self-esteem, while Daly and Burton (1983) found a significant negative correlation between self-esteem and irrational beliefs. Fennel (2004) suggested that the essence of low self-esteem lies in global negative core beliefs about the self, which in REBT are known as self-downing beliefs (Ellis, 1994).

\section{Research Objective}

The main objective of this research is:

i. To study the level of self-esteem

ii. To identify the symptom of low self-esteem

iii. To study the effects of disputation technique towards enhancing the level of self-esteem

\section{Literature Review}

REBT is an action-oriented approach. This approach stresses the role of thinking and belief systems as the root of personal problems. How people think largely determines how they feel and behave (Ellis, 1995). This is a psychoeducational model which emphasizes therapy as a learning process, including acquiring and practicing new skills, learning new ways of thinking and acquiring more effective ways of coping with problems (Corey, 2005).

REBT believes that humans are born with the potential for both rational and irrational thinking. They do not only have predispositions to be self-preserving and actualize their potential for life and growth but also to be self-destructive and have self-damaging habits. People can control their thoughts, feelings, and actions but they must realize what they are telling themselves. Thus, internal dialogue (self-talk) plays a central role in one's behavior (David, Eva \& Macavei, 2005).

A person's belief system is the primary cause of disorders. How they think about events in their lives will affect their emotions and behaviors. Some irrational concepts beliefs and behavioral patterns hold people from this happiness (Ellis, 1995). Irrational beliefs appear from the wrong perceptions of "musts" and "shoulds," which do not correspond with real desires and liking of the person. This contrast results in separation in the mind of a person and makes him unhappy and feel unworthy. In other words, the core assumption of this approach is that it is not the external situations that make us unhappy, but our beliefs toward them and this will affect our self-esteem (Nielsen and Horan, 1996).

Three core demands that contribute to making people miserable are self-demands where one think that one must do well or be approved by significant others, other demands when they feel that they must be treated fairly by others and demands of the world or life where they expect their living conditions to be absolutely the way they want it to be (Gladding, 2009). Other examples from the 11 common irrational beliefs are "It is absolutely essential to be loved or approved by every significant 
other", "some people are wicked and bad, therefore they should be punished or blamed", "it is catastrophic whenever events do not occur as one hopes" and "to be worthwhile, a person must be competent, adequate and achieving in everything attempted". These irrational beliefs when it is not fulfilled will lower the self-esteem (Sava \& Maricutoiu, 2011)

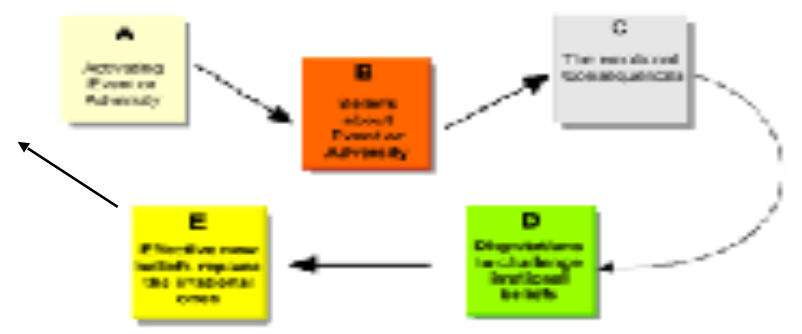

Figure 1: A-B-C-D-E model of REBT

REBT teaches a person to be more flexible with himself and others, to understand the necessity and naturalness of wishes and desires. The A-B-C-D-E model of REBT is central to the approach. A is the existence of an event, B is the person's belief about A which causes $\mathrm{C}$, the emotional and behavioral consequence or reaction of the individual. $\mathrm{D}$ is disputing by application of the method to help client challenge the irrational beliefs and eventually bringing the client to $\mathrm{E}$, an effective belief which is practical (Ellis, 1995). The goal of this approach is to help a client realize that they can live more rational and productive lives by correcting the mistakes in their reasoning as a way of eliminating undesirable emotions (Corey, 2005).

\section{Disputation Technique}

REBT focuses on examining faulty assumptions and misconceptions and on replacing these with effective beliefs so that the clients learn to accept themselves despite their imperfections and maintain good psychological health (Ellis, 2001a). The aim of this technique is to help a client change his selfdefeating habits or thoughts by teaching the client how to dispute and change the irrational belief. Ultimately, the techniques will be used to replace them with new and more rational beliefs. By using the A-B-C-D-E model proposed by REBT at the beginning of the treatment, it challenges the client to confront irrational beliefs with contradictory evidence that they gather and evaluate, also to help the clients to re-evaluate their rigid beliefs and minimize them while replacing it with more flexible thinking (Ellis, 1995). This technique also intents to help the client understand that their thoughts control their feelings.

The client will be taught to dispute his irrational belief and helped to understand that his thoughts are irrational. The disputation technique includes cognitive disputation and imaginal disputation. Cognitive disputation is aimed at asking the client questions that challenge the logic of the client's belief while imaginal disputation has the client use imagery to examine the situation which has caused the client to become upset (Corey, 2005).

\section{Methodology}

This research is a single case study conducted to investigate the effects of the disputation technique in the enhancing self-esteem of a student with low academic performance. The sample, who has low academic performance, was chosen as the research subject and the treatment procedure was planned out according to the disputation technique based on the Rational Emotive Behavior Therapy (REBT). In addition, a single case study is used to answer the question "Was therapy carried out effectively?" as described by McNamara (2000).

Before the start of the treatment, the subject underwent a pre-test which was the Rosenberg SelfEsteem Scale to determine the level of the subject's self-esteem. The method employed was the quantitative method. In order to identify the symptoms of low self-esteem in the subject, both qualitative and quantitative methods are used. During the counseling sessions, interviews and observations were conducted by the counselor to identify the symptoms. The constructs in the Rosenberg Self-Esteem Scale were used to support the observation made and also reference to the DSM IV was accomplished to check for the symptoms.

After the fourth counseling session, the first post-test was carried out. Subsequently, after finishing the treatment which was in the sixth session, post-test 2 was done using the Rosenberg Self-Esteem Scale. This was to facilitate the data collection process and to compare the scores between the pre-test 
and post-tests in order to study the effects of disputation technique on the subject. To further support the findings, the qualitative research method was also employed using the counseling sessions' transcripts. Through the data collected, the symptoms before and after the treatment were compared to study the effects of the technique used. Interpretation of the information obtained from the counseling session transcripts and observations were carried out to help understand the effects of the disputation technique to increase the subject's self-esteem.

\section{Sample}

The sampling method used for this research was the purposive sampling. This method was chosen because the sample selection was based on the criteria or characteristics that have been set before the sample was selected. The use of this method was consistent with the definition of purposive sampling where the researcher selected a sample based on his experience and knowledge of the group he wanted to sample as presented by Gay, Mills, and Airasian (2014).

The subject was chosen after he came voluntarily to undergo counseling due to his low academic performance. A pre-test was carried out using the Rosenberg Self-Esteem Scale to identify the selfesteem level of this subject after an explanation was given on how to do the test. The research subject was a Malay youth aged 19 years old who fulfilled the characteristics set by the researcher:

i) A student with low academic performance.

ii) Has low self-esteem score in the Rosenberg Self Esteem Scale test (score is below 20).

iii) Can write and read.

iv) Voluntarily agree to participate in this research.

\section{Instrument}

Rosenberg Self-Esteem Scale is a measurement tool that is commonly used in previous studies related to self-esteem both internationally and in Malaysia (Nazirah Zuman et al., 2012). Rosenberg (1965) had determined the score for the 10 items based on four options from "strongly agree" to "strongly disagree." High reliability was reported in this measurement tool with a coefficient alpha of 0.74 . This scale had been tested and had a very high validity where the correlation test result was within 0.82 to 0.88 , and Cronbach's alpha for various samples was in the range of 0.78 to 0.88 (Schmitt \& Allik, 2005).

\section{Treatment Procedure}

In this study, a total of six counseling sessions were conducted with the subject/client which lasted between 30-45 minutes for each session. The treatment procedure follows certain steps in the counseling sessions. According to Gladding (2009), the counseling process has six steps which are providing pre-session, build relationships, explore and analyze the problem, identify the cause of the problem where treatment technique is employed and termination decision. In addition, the researcher had also sought written permission and consent to record the counseling sessions from the subject/ client.

\section{Data Analysis}

The subject's self-esteem level was analyzed using descriptive analysis. This analysis is conducted by comparing the total scores obtained in the pre-test and post-test using the Rosenberg Self-Esteem Scale based on the score. Furthermore, the symptoms and the effects of the disputation technique in enhancing subject's self-esteem are established by analyzed using content analysis.

\section{Results and Discussions}

\section{Level of Self-Esteem in Student with Low Academic Performance}

The subject involved in this research was a foundation year student who had a low academic performance based on his last examination result which was CGPA below 2.80. Based on this characteristic, the level of self-esteem in the client was measured using the Rosenberg Self-Esteem Scale before beginning the intervention (pre-test), during the intervention (post-test 1) and after intervention (post-test 2).

Table 1 shows the client's RSES score is 14 in the pre-test and the post-test 1score is 17 . According to Rosenberg (1965), this score indicates a low level of self-esteem. However, in post-test 2, the client 
has a score of 22, which indicates a high score in his self-esteem. For RSES, a score below 20 means a low level of self-esteem and a score below 10 is considered a ver y low level of self-esteem.

The increment in the level of self-esteem by using the disputation technique reported in this study is consistent with the conclusion obtained in the study done by Sava \& Maricułoiu (2011) who conducted the research on undergraduate university students. Sava \& Mariculoiu also found that the disputation of irrational belief within therapeutic interventions a had positive effect on the students' self-esteem.

Table 1: Self-Esteem Score for Pre-Test, Post-Test 1 and Post-Test 2 and the level based on Rosenberg Self-Esteem Scale (RSES).

\begin{tabular}{ccc}
\hline Evaluation & Score & Level \\
\hline Pre-test & 14 & Low \\
Post-test 1 & 17 & Low \\
Post-test 2 & 22 & High \\
\hline
\end{tabular}

\section{Symptoms of Low Self-Esteem of Student with Low Academic Performance}

Based on the transcripts, the symptoms of low self-esteem shown by the client in this research included low self-confidence, downplaying or ignoring his positive quality, tendency to blame himself, negative words to describe himself, inferiority complex which results in avoiding activities involving other people and being embarrassed of himself. The findings from the research showed that the client demonstrated the symptoms of low self-esteem mentioned based on the reports from the transcripts of the counseling sessions.

Low self-confidence meant the client did not have confidence in himself as analyzed in the counseling transcripts. In the first example, the client showed low confidence in his ability to catch up with his study, and in the second example, the client did not have the confidence to ask his lecturer any question. He had low confidence issues within himself and also to interact socially with other people who were indicative of his low self-esteem. It also affected his study because he skipped classes and had no interest in studying.

Downplaying or ignoring his positive quality means the client had given statements to indicate that he downplayed his ability or positive quality by stating that it was just luck when he did achieve anything, or other people can also do it. Thus, there was nothing special about his achievement. This was also an obvious symptom of low self-esteem.

The tendency to blame himself meant the client also had the tendency to blame himself if anything went wrong with him or even other people like his mother. He felt guilty and kept blaming himself for everything that went wrong in his life without looking at the real issue, and he blamed himself for disappointing his mother and the failure to meet her expectations.

Negative words to describe himself meant the clients had used negative words to describe himself during the session. As evident in the counseling transcriptions, the client called himself stupid for not being able to perform in his exams. Other than that, the client also described himself as unworthy, and he repeated these negative characters a few times during the sessions.

The client demonstrated inferiority complex by saying his friends were much greater than him and that he was not suited to play or study with them. The client also tried to avoid activities that involved other people due to his inferiority complex. All these thinking and actions portrayed symptoms of low self-esteem in the client.

Being embarrassed of himself meant that client felt embarrassed of himself because he thought he was not clever compared to others, and he also felt embarrassed as he was incapable of fulfilling the hope of his parents. The client looked down on himself and embarrassed to be himself.

These symptoms of low self-esteem were also reported by other studies (Lawrence, 1985). The activating event that produced the irrational belief which in the end decreased the level of self-esteem in the client in this research was his poor SPM examination result which was not what he expected. He had the irrational belief that to be a worthwhile person, he must achieve and succeed at whatever he does and must not make any mistake. He also must also meet other people's expectations to make them proud of him.

Therefore, when he had a low academic performance, this irrational beliefs resulted in consequences which were the symptoms mentioned earlier. Hence they lowered his self-esteem. The irrational belief the client had was similar to the belief reported by Nielsen and Horan (1996) who 
found that two specific irrational beliefs which had continued to predict low self-esteem in the young population were the demand for approval from those significant to them, and they had to be successful in everything they do without making any mistakes.

\section{The Effects of Disputation Technique on Self-Esteem of Student with Low Academic Performance}

In general, the application of the disputation technique based on REBT model had given a positive impact on increasing the level of self-esteem in the client. To further observe the effect of disputation technique on the client's self-esteem, the score of Rosenberg Self-Esteem Scale and the transcripts from the counseling session were analyzed.

Based on the RSES taken by the clients which were pre-test, post-test 1 and post-test 2, the analysis made has shown an increment in the score which indicates a raising level of self-esteem in the client after undergoing the intervention. The increment of RSES score is shown in Figure 2.

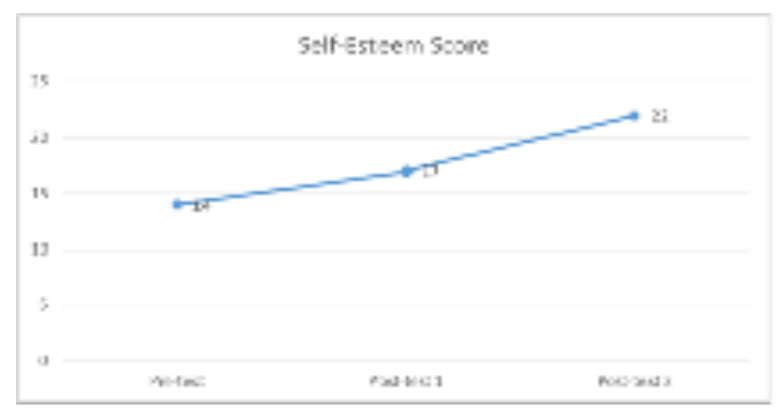

Figure 2: Client's Self-Esteem Score based on Rosenberg Self-Esteem Scale (RSES)

Thus, based on the result of RSES score, it can be concluded that the application of disputation technique is capable of increasing the level of self-esteem in the client. Even though the increment shown is not aggressive, the researcher believes that if the client continues to apply the technique taught over a longer period of time, a higher RSES score can be obtained. Hence, improving the client's level of self-esteem.

\section{The Effect of Disputation Technique on Client's Cognitive}

The client has shown more rational thinking and positive perception towards a situation which previously would have made him feel so upset, especially if it involves his study. The client has been using the rational card where he wrote the old belief on the top and the new belief at the bottom of the card. He agreed to carry the card with him for a week and read it eight to ten times a day. It can be observed that the client feels motivated and think that he is not a failure when he disputes the irrational belief and replaces it with the new belief. He has also acknowledged that he has established success on certain occasion.

\section{The Effect of Disputation Technique on Client's Emotion}

In terms of emotion, the client has started to show interest in co-curricular activity again and feels excited and happy to meet other people. The client has also mentioned positive emotions where he feels calmer thinking about his study and himself. The client also stated that he feels less embarrassed of himself and to his family.

\section{The Effect of Disputation Technique on Client's Behaviour}

The client has mentioned that he is now joining a debate club and starting to play sports again. This shows an improvement in the client's interest to interact socially with his peers and his behaviour. The client has also shown changes in his behavior by consistently going to his classes and tutorial. He had also attempted to do tutorial questions before going to class. This is an improvement compared to before the intervention was carried out.

From the observation, it can also be witnessed that the client initially showed symptoms of distress or embarrassment by often looking down when he was answering the questions given. His expressions also looked sad or unhappy in the earlier sessions. However, after the intervention had been carried out, starting from session four, the client started showing happier expressions. He was able to laugh 
and often smile when discussing his issues. This showed improvement in terms of the client's nonverbal body language.

\section{The Effect of Disputation Technique on Client's Self-Esteem}

The client had a voiced more positive view of himself like he has good qualities, he is capable of doing things like others and feels that he is useful compared to before he underwent intervention. These were symptoms of high self-esteem as analyzed from the counseling transcriptions. This technique is effective for the client because REBT aims for unconditional self-acceptance irrespective of their traits, behaviors, achievement or how other people see them (Pace, 2006; Nielsen and Horan, 1996). Thus, even though the client has low academic performance, he can still see himself as worthy and equal to others based on the good qualities he has. When the client disputed his irrational belief by replacing it with a new belief, he was able to acknowledge his previous achievements.

Thus, by accepting himself as who he is, the client has managed to increase his self-esteem. This technique helped him to develop self-acceptance by enhancing the rational self-talk hence assisting the improvement of self-esteem. This finding supports the study made by Davies (2006) which found correlational proof that irrational thinking is associated with conditional self-acceptance (which is linked to self-esteem), whereas rational thinking is associated with unconditional self-acceptance.

\section{Conclusions}

As a conclusion, the symptoms of low self-esteem have also been successfully identified, and the result shows that the application of the disputation technique is effective in enhancing the self-esteem of a student with low academic performance through the analysis of cognitive, emotion and behavior changes.

\section{References}

Coopersmith, S. (1967). The Antecedents of Self-Esteem. W. H. Freeman \& Co: San Fransisco, USA.

Corey, G. (2005). Theory and Practice of Counseling and Psychotherapy. Thomson Brooks/Cole:

Daly, M. J., \& Burton, R. L. (1983). Self-esteem and irrational beliefs: An exploratory investigation with implications for counseling. Journal of Counseling Psychology, (30), 361-366.

David, D., Szentagotai, A., Eva, K. \& Macavei, B. (2005). A Synopsis of Rational Emotive Behavior Therapy (REBT); Fundamental and Applied Research. Journal of Rational-Emotive and CognitiveBehavior Therapy, 23 (3) 175-221.

Davies, M. F. (2006). Irrational beliefs and unconditional self-acceptance. Correlational evidence linking two key features of REBT. Journal of Rational-Emotive and Cognitive Behavior Therapy, (24): 113-124.

Ellis, A. (1994). Reason and emotion in psychotherapy (2nd Ed.). Birch Lane: Secaucus, NJ.

Ellis, A. (1995). Changing Rational-Emotive Therapy (RET) to Rational Emotive Behavior Therapy (REBT). Journal of Rational-Emotive and Cognitive-Behavior Therapy, 13 (2): 85-89.

Ellis, A. (2001a). Feeling better, getting better and staying better. Prometheus Books: Amherst, NY.

Fennell, M. (2004). Depression, low self-esteem and mindfulness. Behaviour Research and Therapy. 42(9): 1053-1067.

Gay, L.R, Mills, G. \& Airasian (2014). Educational research: Competencies For Analysis and Application (10th.ed.). Prentice Hall: New Jersey.

Gonzales-Mena, J. (2009). Child, Family and Community: Family-Centered Early Care and Education. Pearson Education Inc, 206-208.

Gladding, Samuel T. (2009). Counseling: A Comprehensive Profesion (6th.ed.). Prentice Hall: New Jersey.

Gonzalez, J. E., Nelson, J. R., Gutkin, T. B., Saunders, A., Galloway, A., \& Shwery, C.S.(2004). Rational emotive therapy with children and adolescents: A meta-analysis. Journal of Emotional and Behavioral Disorders, (12): 222-235.

Greiger, $R$. (1990). Self-concept, self-esteem and rational-emotive theory: A brief perspective. Rational Living, (10): 13-17.

Hamachek, D. (1990). Self-concept and school achievement: Interaction dynamics and a tool $f$ o $r$ assessing the self-concept component. [Electronic Version], Journal of Counseling \& Development, 73(4), 419-425.

Henderson, (1991) [Dissertation]. The Relationship among Academic Performance, Academic Achievement, Social Acceptance and Self-esteem. University of Alabama Birmingham. 
Jordan C.H., Spencer, S.J. and Zanna M.P. (2005) Types of High Self-Esteem and Prejudice: How Implicit Self-Esteem Relates to Ethnic Discrimination among high explicit self-esteem individuals. Pers Soc Psychol Bull 2005; (31): 693.

Lawrence, D. (1989). Improving Self-Esteem and Reading. Journal of Educational Research, 27(3): 194-200.

May, W. (2002). Self-Esteem in Children: Considerations in Measurement and Intervention. American Journal of Occupational Therapy, 44(8), 729-734.

McClure, A.C., Tanski, S.E. \& Kingsbury, J. (2010). Characteristics Associated with Low SelfEsteem Among US Adolescents. Academic Pediatrics, 10 (4): 238.

McNamara, J. (2000, November). Winging it Through Improvisation. Paper presented at the MAHPERD Conference, Michigan.

Nazirah Zuman, Kartini Alias, Khairil Anuar Md Isa \& Ajau Danis (2012). Relationship Between Eating Behaviors, Self-Esteem and Academic Achievement among Lower Secondary School School Students in Meru Klang, Malaysia. Asian Journal of Clinical Nutrition 4(4):132-141

Nielsen, D.M. \& Horan, J.H. (1996). An Attempt to Improve Self-Esteem by Modifying Specific Irrational Beliefs. Journal of Cognitive Psychotherapy: An International Quarterly, 10 (2).

Pace, R.R. (2006). Effects of Rational Emotive Behaviour Therapy on Self-Esteem and Depression Within Faith-Based Populations. Texas Southern University, Dissertation for Doctor of Education

Rosenberg, M. (1965). Society and the adolescent self-image. Princeton University Press: Princeton, NJ.

Rosenberg, M. \& Schooler, C. (1989). Self-esteem and adolescent problems: modeling reciprocal effects. American Sociological review: (54): 1004-1018.

Sava, F.A \& Maricułoiu, L.P. (2011). Implicit and Explicit Self-Esteem and Irrational Beliefs. Journal of Cognitive and Behavioral Psychotherapies, 11 (1): 97-111.

Schmitt, D. P. \& Allik, J. (2005). Simultaneous Administration of the Rosenberg Self-Esteem Scale in 53 Nations: Exploring the Universal and Culture-Specific Features of Global Self-Esteem. Journal of Personality and Social Psychology, 89 (4): 623-642.

Shokraii-Rees, N. (2003) The Self-Esteem Fraud: Why Feel Good Education Does Not Lead To Academic Success. Retrieved July 15, 2004 from, Center for Equal Opportunity Web site:http:// www.ceousa.org/self.html 